\title{
A transgressão pela estética da falência na prosa poética de Konstantinos Kaváfis
}

\author{
Fernanda Lemos de Lima (UERJ) \\ Luciana Póvoa (UERJ)
}

\begin{abstract}
Resumo
No presente artigo, pretende-se abordar a prosa poética do poeta helênico Konstantinos Kaváfis, buscando compreender como a através de uma estética da falência o poeta constroe uma produção literária que prima pela transgressão, tão cara à modernidade. Para tanto, recorreremos a autores como Charles Baudelaire e Walter Benjamin, sensíveis observadores de seus tempos.

Palavras-chave: Kaváfis - poesia em prosa - modernidade
\end{abstract}

\begin{abstract}
In this article, we intend to approach the poetic prose of the Hellenic poet Konstantinos Kaváfis, seeking to understand how through an aesthetic of bankruptcy the poet builds a literary production that presses for the transgression, so dear to modernity. To do so, we will appeal to authors like Charles Baudelaire and Walter Benjamin, sensitive observers of their times.
\end{abstract}

Key-words: Kaváfis - poetic prose - modernity

A transição do século XIX em direção ao XX designa-se como um momento histórico em que a Europa e o Oriente próximo sofrem mudanças, rupturas estruturais e novas configurações em âmbito geográfico e cultural. Nesse contexto, a Grécia Moderna assiste a uma série de mudanças políticas, incluindo diversas derrotas militares e uma contundente desilusão relativa ao projeto da Grande Idéia - uma proposta de reconquista da Constantinopla perdida para o Império Turco-Otomano. A quimera de um factível reconstruir de um mundo helênico e de um império que remontasse à grandeza do mundo Bizantino ruiu com a derrocada de exércitos esfacelados pelos desastres militares sofridos pela Grécia. 
Nesse momento, a literatura que se faz em Atenas segue a conduta literária tutorada por Kostis Palamás, na auto-intitulada Escola de Atenas, em que é possível observar a exploração de temáticas voltadas para construção e recuperação de um imaginário da maná mou Elláda ${ }^{25}$. Entretanto, distante dessa circunstância, na diáspora grega, desenvolve-se a demiurgia poética daquele que viria a reconfigurar as Letras NeoHelênicas e a ser reconhecido como um dos protagonistas da poesia grega moderna: Konstantinos Petros Fotiades Kaváfis.

Na Alexandria do Egito, Kaváfis acaba por desenvolver uma obra poética com dicção própria e, especialmente, inscrita na Modernidade - a mesma anunciada por Charles Baudelaire, um dos instigadores literários do poeta alexandrino.

A hipótese suscitada inicialmente no projeto de pesquisa que ensejou as exegeses desenvolvidas ao longo do presente texto remetia a pontos relevantes para a compreensão da obra kavafiana como um todo - e, em particular, dos poemas em prosa.

Dentre eles, destaca-se a idéia de que Kaváfis fermentou-se em um espaço multicultural, em que idiossincrasias são dissolvidas em uma cidade elaborada por mitos: Alexandria do Egito não é um apenas, mas sim o cânone da preposição com: diversas etnias e culturas são colocadas na transcendência de nacionalidades em que elos estéticos e poéticos perpassam tais barreiras no contínuo processo de angústias e falências intrínsecas ao sujeito na busca incessante do verbo edificar, mesmo que esse processo esteja fadado ab initio a essa duradoura e ininterrupta falência.

Essa é a questão de partida para estipular a hipótese da angústia e falência nos poemas em prosa kavafianos, ao lado da percepção de que dois dos três escrito estudados podem ser designados como metapoemas que propiciam o entendimento da construção poética mediada pela imaginação e pelo $\operatorname{prazer}^{26}$, o que já anuncia a temática hedonística da obra kavafiana ${ }^{27}$.

\footnotetext{
${ }^{25}$ Termo bastante utilizado na literatura do período em questão para designar o conceito ideológico da "mãe Grécia".

${ }^{26}$ Os dois metapoemas em evidência são $O$ s navios e $O$ regimento do prazer, ambos estudados ao longo do presente ensaio.

${ }^{27}$ A temática hedonística na obra de Kaváfis é muito evidenciada por sua poesia de caráter homoerótico. Para um estudo mais aprofundado, ver LIMA, Fernanda. Entre quartos, ruas e cafés: a poesia homoerótica de K. P. Kaváfis. Rio de Janeiro: Nonoar, 2007.
} 
Em paralelo a isso, não se pode olvidar o diálogo intertextual entre diferentes autorias que perpassam a constituição da tessitura verbal de Kaváfis. Dentre elas, destaca-se a vertente simbolista-decadentista da literatura francesa ${ }^{28}$ : em função de sua estadia na Inglaterra e por apresentar um visível e latente interesse pelas diferentes manifestações literárias e artísticas da Europa, Kaváfis desenvolverá não apenas a poesia, mas uma fortuna crítica na qual uma extensa gama autores será examinada.

Sua percepção de mundo aproxima-o da figura baudelairiana que apresenta como traço constituinte a curiosidade generalizada de modo latu sensu. Em seus escritos críticos, Kaváfis debate diferentes temas: a literatura de per si, o teatro e suas configurações, problemas linguísticos contextualizados no modus loquendi grego, chegando a abordar questões políticas como a discussão sobre a devolução dos mármores do Partenon ${ }^{29}$. O poiéo kavafiano parece ecoar o "homem do mundo", com traços da flanerie, em que os diversos instantes prosaicos podem - e devem - ser capturados e reconfigurados em $\operatorname{arte}^{30}$.

O trecho retirado de Sobre a Modernidade, ensaio relevante para a compreensão de uma modernidade in perpetuum mobile configurativo, pode auxiliar na percepção de como o poeta da Alexandria inscreve-se na rubrica da modernidade, especialmente ao tomar o capítulo voltado para a temática dessa espécie nova da artista. Ao comentar a figura de Guys e seu modus operandi artístico, Baudelaire apresenta os elementos que caracterizam essa nova personagem artística:

Quando finalmente o conheci, logo vi que não se tratava precisamente de um artista, mas antes de um homem do mundo. Entenda-se aqui, por favor, a palavra artista num sentido muito restrito, e a expressão homem do mundo num sentido muito amplo. Homem do mundo, isto é, homem do mundo inteiro, homem que compreende o mundo e as razões misteriosas e legítimas de todos os costumes ${ }^{31}$.

Além de compreender a imagética cotidiana, esse homem do mundo traria em sua constituição o elemento da curiosidade ilimitada e, justamente, seria esse o dínamo

\footnotetext{
${ }^{28}$ Cf. ROBINSON, Christopher. C. P. Cavafy. Bristol: Bristol Classical Press, 1988, p.2.

${ }^{29}$ Cf. KAVÁFIS, K.P. Ta Pezá (1882-1931). Atenas: Íkaros Ekdotikí Etairía, 2003.

${ }^{30}$ A figura do "homem do mundo", que amplia a percepção do artista que mergulha na observação do cotidiano e, aparentemente, desprovido de valor estético. Cf. BAUDELAIRE, Charles. Sobre a modernidade. São Paulo: Paz e terra, 1996, p. 18.

${ }^{31}$ Cf. BAUDELAIRE, Charles. Opus cit., p. 16.
} 
catalisador de seu gênio. Além desse componente, algo é capaz de potencializar essa curiosidade quase patológica: a percepção de um mundo a ser explorado sempre por novas ópticas, em que tudo transforma-se em descoberta, por mais trivial que possa parecer.

É precisamente a forma como o corriqueiro, o cotidiano, o trivial e até mesmo o vulgar são abordados e percebidos em seus instantes é faz desses elementos matéria poética ${ }^{32}$. Debate-se, portanto, a arte que tem como centro a percepção do presente.

Nesse contexto de uma Modernidade emergente, inscreve-se a escrita kavafiana em busca de linguagem e temáticas próprias, que fujam do exótico estereótico oriental e que elevem a banalidade de um arrumar de gavetas $^{33}$ à condição de poesia. Kaváfis torna sua poesia representante de seu presente ao colocar as temáticas clássicas em um segundo plano - como um pretexto para refletir, poeticamente, a respeito dos conflitos de seu tempo - para que seja possível remodelá-las criticamente, abordando a representação dos jovens anônimos dos primeiros anos do século XX. E mesmo ao retomar a Grécia antiga, já não haverá o espaço para a celebração heróica, mas somente para o reconhecimento de que a falência paira, perpétua, como ameaça e certeza silenciosa ${ }^{34}$.

A poiésis kavafiana configura-se, assim, sob o signo de tal falência e se inscreve na expressão da modernidade, em que o caráter heróico traz a fragilidade, a experiêncialimítrofe do sedutor suicadere como único ato possível. Esse entregar-se às experiências radicais ou a opção pela retirada de sua própria existência do contexto local estarão presentes em dois dos três poemas em prosa que configuram o objeto de exegese da presente investigação.

A obra poética de K. P. Kaváfis não é de modo algum extensa. Ao contrário, há uma produção que prima pelo cuidado no lapidar do verso, granjeando a forma mais preciosa e singular, como diamante a ser recortado até atingir o esplendor máximo de brilho. $\mathrm{O}$ procedimento poético do Alexandrino inclui várias reescrituras de um mesmo poema até que a forma final seja atingida.

\footnotetext{
${ }^{32}$ Idem, p. $65-66$.

${ }^{33}$ Cf. poema em prosa "O Vestuário" a ser analisado no decorrer da presente pesquisa.

${ }^{34} \mathrm{Um}$ dos poemas que ilustra perfeitamente esse modus operandi é Termópilas, em que toda a grandeza do exército espartano está fatalmente ameaçada pela figura do fraco Efialtes - o traidor que informa a posição dos espartanos aos inimigos persas.
} 
É interessante perceber como o poeta guarda sua produção de olhos vulgares, com exceção dos escritos de crítica literária, publicados em revistas de Alexandria. De modo geral, poucos foram os poemas impressos em folhas avulsas e oferecidos a olhares especialmente escolhidos por Kaváfis.

Esse transitar entre o público e o privado de maneira tão diversa acaba por atiçar a imaginação, uma vez que o poeta poderá extrair do trivialmente cotidiano um instante do Belo e, concomitantemente, negar à óptica vulgar o amplo acesso a seus escritos poéticos.

Poder-se-ia refletir a respeito de um trânsito do poeta Kaváfis entre a postura do flaneur - que observa a multidão e dela extrai momentos singulares e irrecuperáveis, promovendo um diálogo com o Impressionismo - e a imagem do dândi - anacrônico por sua postura aristocrática em um mundo cujo seu espaço não mais existe.

É importante esclarecer que o dândi seria o componente centrado na sua autoconstituição e que se coloca à margem do processo produtivo, voltado apenas para a construção de sua autonomia. Assim, o espaço vulgar adentrado pela persona do flâneur para o recolhimento da experiência a ser transfigurada em matéria poética estaria ligada à feição da flaneirie kavafiana e o afastamento de sua criação poética de olhares banalizados e banalizantes estaria ligado à sua postura aristocrática deslocada.

Entretanto, um problema surge na biografia de Kaváfis para que o mesmo seja compreendido como dândi: ele é um funcionário público. Está, portanto, inserido no processo produtivo, não sendo a figura do deslocado, a não ser como imagem de poeta em seu preciosismo e a ocupação viciada das personae poéticas desenvolvidas, nas quais o amor-prazer apresenta-se como necessária e inevitável experimentação, como será visto no poema em prosa $O$ regimento do prazer. $\mathrm{O}$ dândi kavafiano coincidiria com o conceito baudelairiano relativo ao mesmo personagem: ele empreenderia uma busca pelo amor-prazer, configurado na ocupação propiciada pelo ócio em que vive este dândi $i^{35}$.

A obra kavafiana - seja em sua elaboração, seja em seu modo de divulgação -apresentase, indubitavelmente, como produto da Modernidade: um momento de produção cultural que se configura em mudança, que registra o movimento em seus instantes

\footnotetext{
${ }^{35}$ Cf. BAUDELAIRE, opus cit., p.45.
} 
fugidios - como na proposta Impressionista de arte - e traz a feição da falência como condição do humano. A partir dessas considerações, proponho a investigação em torno dos três poemas que apresentam a forma ousada da prosa poética, como é designada por Charles Baudelaire e Walter Benjamin. ${ }^{36}$

Trata-se das três únicas composições poéticas em prosa na obra de Konstantinos Kaváfis, poemas cuja datação não é clara, que traem um diálogo com o Baudelaire evocado algumas vezes pelo poeta ao longo de sua obra, seja por suas traduções, seja por um comentário em seus escritos íntimos, seja ainda por uma comparação que a essa investigação realiza e que aproxima da imagem poietés (homem do mundo) com a de lutador - o esgrimista baudelariano e o peão valente de Kaváfis ${ }^{37}$.

Os três poemas - "Os navios", "O regimento do prazer" e "Vestuário" - estão inseridos na coleção de Poemas Escondidos e são os únicos exemplares dessa forma na obra de Kaváfis.

É interessante mencionar um instigante texto de Baudelaire que traz um comentário em relação aos poemas em prosa. Escrito como parte de uma dedicatória à Arsène Houssaye, é citado por Walter Benjamin em seu ensaio A Modernidade ${ }^{38}$ :

Quem dentre nós já não terá sonhado, em dias de ambição, com a maravilha de uma prosa poética? Deveria ser musical, mas sem ritmo ou rima; bastante flexível e resistente para se adaptar às emoções líricas da alma, às ondulações do devaneio, aos choques da consciência. Esse ideal que se pode tornar idéias fixa, se apossará, sobretudo, daquele que, nas cidades gigantescas, está afeito à trama de suas inúmeras relações entrecortantes.

Ao percorrer as linhas de Baudelaire, é possível estabelecer a criação de um percurso direcionado à exegese dessa produção curta em Kávafis. É postulado o que estabelece a ambição da prosa poética, em que os elementos se interpenetram: a musicalidade, as emoções líricas, os devaneios e os choques de consciência.

\footnotetext{
${ }^{36}$ Benjamin, em seu ensaio intitulado 'A Modernidade', menciona a proposta de Baudelaire para "render justiça também na prosa a essas experiências prosódicas", nas quais estaria inserida a metáfora do esgrimista. Cf. BENJAMIN, Walter. A Modernidade. In:__. Obras escolhidas III - Charles Baudelaire, um lírico no auge do capitalismo. São Paulo: Brasiliense, 1994, p. 68-69.

${ }^{37}$ Em um escrito de Kaváfis denominado pela crítica como "Arte poética", há a comparação do poeta com a figura do peão, que luta para cruzar o tabuleiro, mesmo sabendo da possibilidade de derrota que ronda seu ato. $\mathrm{O}$ esgrimista baudelairiano seria aquele que também luta com a matéria poética para que a mesma plasme-se em obra de arte perene no tempo.

${ }^{38}$ BENJAMIN, Walter. A Modernidade. In: Obras escolhidas III - Charles Baudelaire, um lírico no auge do capitalismo. São Paulo: Brasiliense, 1994, p. 68-69.
} 
Se Kaváfis não vive a cidade gigante, vive a Alexandria do anonimato em seus poemas, uma vida na penumbra que é condição inalienável para a fruição dos vícios e prazeres na noite - os mesmos que um dia tornar-se-ão fibra de tecido poético elaborado e que clamam ao eu-poético sua participação nessa idonilatria ${ }^{39}$.

Nos três poemas em prosa, podemos determinar um caminho de elementos não estanques, assim como os devaneios de Os navios, os itens clássicos amalgamados ao cotidiano de o $O$ regimento do prazer e o choque da consciência do tempo que escorre indelevelmente em Vestuário.

No escrito $O$ regimento do prazer, há um desfile a apresentar estímulos múltiplos à sinestesia inerente ao pacto emissor-receptor, os quais "arrepiam e estremecem" 40. Dentre eles, encontra-se, além da imagética salientada e epidermializada nas linhas do poema em questão, o apelo musical que atua como uma espécie de convocação àqueles que "não são tolos" 41 . A aceitação da entrega aos prazeres, da incorporação ao "regimento" - imagem bélica impregnada do sensual - que convoca a todos, acaba por traduzir uma propensão à criação poética celebradora do prazer de todas as espécies sem quaisquer empecilhos morais ou sociais.

Não permita que qualquer mérito sombrio carregue-o. Não acredite que qualquer imposição restrija-o. Seu dever é ceder, ceder sempre ao desejo, que são as criaturas cabais das divindades perfeitas. Seu dever é alistar-se como um fiel lacaio, com simplicidade cardíaca, quando passar o regimento do prazer com música e estandartes. ${ }^{42}$

Importante observar como no poema em prosa em questão também figura a temática kavafiana de exaltação dos desejos proibidos, condenados. A eles, é preciso ceder incondicionalmente, tornando-se servo fiel de divindades perfeitas. O que faz lembrar o discurso de Oscar Wilde, em especial, a máxima "A melhor maneira de vencer uma tentação é ceder a ela", o que traduz a exaltação do hedonismo tão ligada à figura do Dândi - uma das figuras heróicas da Modernidade ${ }^{43}$. Interessante, ainda, é perceber

\footnotetext{
${ }^{39}$ Termo cunhado para a presente pesquisa e que une o conceito de prazer ao de adoração religiosa, como será percebido na interpretação do poema em prosa "O regimento dos prazeres".

${ }^{40}$ Trecho do poema "Regimento dos prazeres" de K. P. Kaváfis, minha tradução. Todas as traduções, salvo indicado, são de minha autoria.

${ }^{41}$ Idem.

${ }^{42}$ Idem.

${ }^{43}$ Cf. BENJAMIN, Walter. Opus cit., p. 94.
} 
nessa fidelidade algo de religioso serviço ao prazer, especialmente no parágrafo final do poema:

Não se deixe lograr pelos blasfemos que dizem ser a ocupação perigosa e trabalhosa. O serviço do sensual-prazer é uma constante alegria. Exauriu-lhe, mas o fez mediante sublimes inebriações. E, por fim, quando tu encontrar-te na rua, mesmo assim a sua fortuna será invejável.

Nesse crescendo em que se desenrola o poema, o leitor depara-se com o envolvimento proposto a essa quase-religião do prazer, submetida às sensações que a paradasuspensão provoca, a justificativa de se ceder ao apelo da mesma - sobretudo se aquele que a assiste não é um tolo -, o descrédito das limitações oferecidas pelas "teorias de justiça” e, finalmente, como culminância da criação desse que também se configura como mais um metapoema em prosa, as Formas - modeladas pelos desejos vividos serão os seguidores do cortejo fúnebre daquele que não temeu servir ao prazer:

Quando o seu funeral passar, as Formas as quais o seu desejo modelou derramarão rosas brancas e lilases sobre o seu caixão, levantarão nos ombros dos jovens deuses do Olimpo, e enterrá-lo-ão no Cemitério do Imaginário, em que branqueiam o mausoléu da poesia.

Os deuses do Olimpo, imersos em toda a sua juventude, parecem trazer alguma reminiscência da tradição clássica, o que faz rememorar a presença clássica deslocada na poesia baudelairiana em sua transição e configuração da modernidade. Kaváfis, em seu experimentar poético, transita pelo imaginário do simbolismo em que o poeta figura como aquele que pode interpretar os símbolos e vivências os quais o homem ordinário não é hábil e capaz de abraçar. Diana Haas discute essa posição do poeta como esse intérprete cuja poesia transita por uma estética "mística e simbólica"44, especialmente no que diz respeito aos poemas escritos até 1903 - período em que Kaváfis elabora uma tradução livre de "Correspondance". O trânsito da imagem do poeta morto elevado pelos jovens deuses olímpicos trai a imagem mística de ascensão do Poeta, aquele que leva a experiência carnal do prazer à esfera do divino - do mundo material ao mundo etéreo - e, ao mesmo tempo, aquele que assim torna privilegiado o lugar do criador do verbo poiéo, cujo túmulo é guardado como um sagrado sepulcro no cemitério do

\footnotetext{
${ }^{44}$ HAAS, Diana. Le problème religieux dans l'oeuvre de Cavafy - Les annees de formation (1882-1905). Paris: Presses de L'universitè de Paris-Sorbonne, 1996.
} 
imaginário $^{45}$, pela poesia que sua experiência de prazer tem a probidade e aptidão de gerar.

A idéia de um locus do imaginário, da maneira como se promove a construção poética é tema, igualmente, do poema em prosa "Os navios", no qual se alude à árdua tarefa da produção poética, da travessia entre a imaginação e o papel $^{46}$. Fala-se, portanto, da áspera e espinhosa tarefa do criador, daquele que forjará as formas e, sobretudo, da travessia entre o imaginário recolhido até o porto-papel no qual a forma final poética acaba por plasmar-se.

A travessia perigosa, em que o naufrágio parece ser o destino quase inevitável de todas as embarcações, assemelha-se à figura do peão que vence cada etapa do tabuleiro de xadrez e acaba encontrando termo de combate às mãos da terrível rainha: eis o jogo poético, o desafio permanente do poeta kavafiano, anunciado na Arte Poética ${ }^{47}$, e que parece ecoar a imagem do esgrimista - o homem do mundo baudelairiano de Sobre a Modernidade ${ }^{48}$. A criação poética é combate, travessia tensa, perigosa, repleta de inevitáveis naufrágios. Ao poeta, resta a busca e a compreensão de que a preciosidade resultante se dá, justamente, pelas falências do caminho:

Felizmente, tais navios são muito raros. Apenas dois ou três vemos ao longo de toda nossa vida. Esquecemos deles rapidamente. Quão brilhante é sua visão, quão rápido é o seu esquecimento ${ }^{49}$.

Observa-se a valorização da raridade com que tais navios chegam a aportar. Entretanto, são intensos, rápidos - entretanto permanentes - e retornam pelo auxílio de um elemento fundamental da poética kavafiana: a memória.

E quando passam alguns anos, sejam alguns dias - assim que, às vezes, de modo indolente vemos a luz e escutamos o silêncio eventualmente retornaram para nossa escuta mental com umas voltas entusiasmadas. Não as reconhecemos de princípio e tiranizam nossa memória, lembrando-nos de que as escutamos antes. Depois de muito labor, acorda a velha recordação e lembramos o que aquelas voltas eram daquela canção que cantavam os marinheiros, belos como os

\footnotetext{
${ }^{45} \mathrm{Cf}$. poema $O$ regimento dos prazeres, no anexo do presente estudo.

${ }^{46} \mathrm{Cf}$. poema Os navios, no anexo do presente estudo.

${ }^{47}$ Cf. KAVÁFIS. K. P. Arte poética. Rio de Janeiro: Horus Educacional, 2008, p. 47.

${ }^{48}$ Cf. BAUDELAIRE, Charles. Sobre a Modernidade. Rio de Janeiro: Paz e Terra, 1996, p.23-24.

${ }^{49}$ Cf. poema Os navios, no anexo do presente estudo.
} 
heróis da Ilíada quando tomavam os grandes e sublimes navios e seguiam adiante - quem sabe para onde ${ }^{50}$.

O labor, alimentado pela recordação tirânica, traz o reconhecimento de um canto que remonta à literatura primordial da Ilíada, cuja imagem dos belos heróis é evocada. Novamente, a construção poética se vale da base clássica em uma forma não canônica, mas experimental e, talvez exatamente por isso, com a mesma incerteza de caminhos poéticos.

E surge a possibilidade de uma restrição da poesia devido às limitações do tempo e da sua sociedade. Essa alusão recorre na poesia kavafiana e ressurge nesse poema em prosa como um lamento, diferente da exaltação à quebra de tais limites dos poemas estudados em parágrafos anteriores:

Pena, pena é outra coisa. É quando tomam alguns grandes navios, com jóias de corais e velas de ébano com grandes bandeiras brancas e vermelhas içadas, cheios de tesouros, os quais nem se aproximarão do porto, seja porque todos os bens que trazem são proibidos, seja porque o porto não tem profundidade suficiente para deixá-los passar. E seguem seus caminhos. Um vento favorável sopra sobre os tecidos das velas, o sol vitrifica o esplendor do ouro de suas proas, afastam-se calma e magnificamente, afastam-se de nós completamente e de nosso limitado porto ${ }^{51}$.

A idéia de que as mercadorias dos navios da imaginação sejam proibidas ou de que o porto não tenha profundidade suficiente podem aludir tanto às limitações sociais quanto às dos próprios artistas que se deixam restringir pelo seu tempo, talvez por sua incapacidade de ter mais "profundidade poética", de aceitar o risco do proibido ou da inspiração que se oferece, mas sem hora marcada.

O terceiro poema em prosa,"Vestuário", não reflete sobre a criação poética, mas trata da passagem do tempo e do caráter efêmero da existência humana. A imagética conduzida pelas vestes a serem arrumadas em receptáculos preciosos, separadas pelas cores "azuis, vermelhas, amarelas, azuis novamente, todavia, desbotadas" - traduzem a passagem do tempo pelo invólucro-pele-veste a ser guardada com piedade $e^{52}$, para, em

\footnotetext{
${ }^{50}$ Idem.

${ }^{51}$ Idem.

${ }^{52}$ Cf. poema Vestuário, no anexo do presente estudo.
} 
seguida, a voz poética trajar-se de luto - o negro que dialoga com o fim-de-festa apresentado no parágrafo final:

Completamente encerrada. As mobílias dispersas nos quartos aleatoriamente. Pratos e copos quebrados pelo chão. Todas as velas queimadas até o final. Todo o vinho embriagado. Todos os convidados partiram. Alguns, fatigados, sentar-se-ão sozinhos, assim como eu, em escuras habitações - outros, mais cansados, irão dormir.

O tempo, nesse poema, remete à vulnerabilidade e fugacidade vitais, a mesma vulnerabilidade de que padecem os navios da imaginação, entretanto, o caráter efêmero não se aplica às Formas. Estas permanecerão mesmo após a morte do poeta, desde que ele saiba entregar-se, sem medo de sansões, a todas as experimentações às quais o mundo convida.

Nesse sentido, é possível retomar o conceito de Belo, como cunhado por Baudelaire no ensaio estudado na presente investigação: ele seria a combinação de elementos permanentes com elementos prosaicos, transitórios. Essa elaboração em que o presente e o atemporal combinam-se são capazes de conduzir ao Belo, elemento que transfigura o corriqueiro em uma obra de arte perene:

O belo é constituído por um elemento eterno, invariável, cuja quantidade é excessivamente difícil determinar, e de um elemento relativo, circunstancial, que será, se quisermos, sucessiva ou combinadamente, a época, a moda, a moral, a paixão. Sem esse segundo elemento, que é como o invólucro aprazível, palpitante, aperitivo do divino manjar, o primeiro elemento seria indigerível, inapreciável, não adaptado e não apropriado à natureza humana $^{53}$.

Duas das composições de poesia em prosa trarão essa possibilidade de permanência através da arte, sobretudo, em $O$ regimento do prazer, em que se afirma, como já foi mencionado, a constância e a estabilidade da obra de arte, mesmo após a falência-morte definitiva do poeta.

Interessante observar como, justamente na constatação da falência como constituinte ontológico da condição humana, o poiéo kavafiano faz-se permanência, a qual implica em uma vivência de riscos, de entrega, e de constatação do limite-vital, inscrevendo sua poesia, seja em qual for a forma em que é plasmada, na Modernidade-angústia que o singulariza como um dos principais representantes da literatura neo-helênica, sem

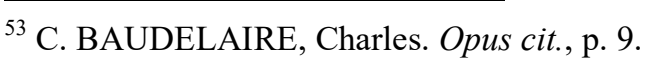


marcas apenas locais, mas guardando em sua poesia uma universalidade ${ }^{54} \mathrm{e}$ atemporalidade que trazem a marca do belo.

A prosa poética kavafiana, particularmente, trará as inegáveis marcas da Modernidade em consonância, conforme visto, com o pensamento baudelairiano e com a critica de Walter Benjamin. Essa forma poética apresenta os traços fortes da sedução de apelos sensoriais e instantâneos - como em $O$ regimento do prazer - o que leva à reflexão sobre a modificação da experiência do indivíduo, cada vez mais rarefeita na Modernidade $^{55}$, e também por essa razão, fadada à falência, na medida em que não há o espaço para os grandes gestos. Resta assim, à poesia o empenho árduo em se tornar algo perene por sua própria condição de Arte, mesmo que essa surja do efêmero movimento de um cotidiano aparentemente desinteressante. Ou melhor, justamente por conta da parente banalidade de roupas maculadas pelas manchas do tempo, é que o poeta pode executar seu duelo e construir a poesia-permanência que o tornará eterno e singular.

\section{Bibliografia:}

BAUDELAIRE, Charles. Sobre a Modernidade. Rio de Janeiro: Paz e Terra, 1996.

BENJAMIN, Walter. A modernidade. In: Obras escolhidas III - Charles Baudelaire, um lírico no auge do capitalismo. São Paulo: Brasiliense, 1994. . Sobre alguns temas em Baudelaire. In: Obras escolhidas III - Charles

Baudelaire, um lírico no auge do capitalismo. São Paulo: Brasiliense, 1994.

HAAS, Diana. Le problème religieux dans l'oeuvre de Cavafy - Les annees de formation (1882-1905). Paris: Presses de L'universitè de Paris-Sorbonne.

KAVÁFIS. K. P. Arte poética. Rio de Janeiro: Horus Educacional, 2008. . Ta Pezá (1882-1931). Atenas: Íkaros Ekdotikí Etairía, 2003.

KEELEY, Edmund. Cavafy's Alexandria. Nova Jersey: Princeton University Press, 1996.

LIMA, Fernanda. Entre quartos, ruas e cafés: a poesia homoerótica de K. P. Kaváfis. Rio de Janeiro: Nonoar, 2007.

\footnotetext{
${ }^{54}$ A perspectiva universalizante da poesia kavafiana é explorada por Edmund Keeley em seu livro Cavafy's Alexandria. Cf. KEELEY, Edmund. Cavafy's Alexandria. Nova Jersey: Princeton University Press, 1996, p. 135 e ss.

${ }^{55}$ Cf. BENJAMIN, Walter. Sobre alguns temas em Baudelaire. In: . Obras escolhidas IIICharles Baudelaire, um lírico no auge do capitalismo. São Paulo: Brasiliense, 1994, p. 107.
} 


\section{$O$ regimento do prazer}

Não fale sobre culpa, não fale sobre responsabilidade. Quando o regimento do prazer passar com música e estandartes; quando arrepiam-se e estremecem os sentidos, é apenas uma tola e irreverente persona que manterá sua distância, que não abraçará uma boa causa, marchando em direção de conquistas e paixões.

Todas as leis da moralidade - mal entendidas, mal aplicadas - são nulas e não podem estar nem por um instante - ao passar o regimento do prazer com música e estandartes.

Não permita que qualquer mérito sombrio carregue-o. Não acredite que qualquer imposição restrija-o. Seu dever é ceder, ceder sempre ao desejo, que são as criaturas cabais das divindades perfeitas. Seu dever é alistar-se como um fiel lacaio, com simplicidade cardíaca, quando passar o regimento do prazer com música e estandartes.

Não confine o seu próprio sujeito em uma habitação, iludindo-o com teorias de justiça, com os preconceitos de recompensa detidos por uma sociedade imperfeita. Não fale, tal é o mérito de meu árduo trabalho e minha dívida a saborear. Assim como a vida é uma herança, e tu não fizeste nada para ganhá-la como recompensa, por isso deve ser um voluptuoso prazer. Não se encerre em casa, todavia abra as janelas, abra amplamente, para que possa ouvir o primeiro som da passagem dos soldados, quando o Regimento do Prazer chegar, com música, e com estandartes. 
Não se deixe lograr pelos blasfemos que dizem ser a ocupação perigosa e trabalhosa. O serviço do sensual-prazer é uma constante alegria. Exauriu-lhe, mas o fez mediante sublimes inebriações. E, por fim, quando tu encontrar-te na rua, mesmo assim a sua fortuna será invejável. Quando o seu funeral passar, as Formas as quais o seu desejo modelou derramarão rosas brancas e lilases sobre o seu caixão, levantarão nos ombros dos jovens deuses do Olimpo, e enterrá-lo-ão no Cemitério do Imaginário, em que branqueiam o mausoléu da poesia.

\section{Os navios}

Da imaginação até o papel. Há uma passagem difícil. Há um mar perigoso. A distância parece curta a uma ótica primeira, e todavia, que longa viagem é, quanto risco diante dos navios, os mesmos que se aventuravam.

O primeiro dano provém da extrema fragilidade da natureza mercantil as quais os navios transportam. Para o mercado da Imaginação, as mais numerosas e melhores coisas são fabricadas, delicados vidros e cerâmicas diáfanas, e com toda a atenção do mundo, muitos quebram-se na rua, e muitos aquebrantam-se quando desembarcam em terra. Todos esses danos são irreparáveis, isso porque não faz sentido voltar novamente ao navio e procurar coisas idênticas. Não há possibilidade de encontrar a mesma loja em que os comprou. Os mercados da Imaginação têm lojas com pompa e luxo, mas não de longa duração. As suas transações são breves, vendem suas mercadorias rapidamente, e dissolvem-se de imediato. É muito raro, em navios que retornam, encontrar os mesmos tipos de coisas exportadas.

Um outro dano surge dos maiores navios. Partem dos portos dos abundantes continentes carregados, e depois, ao encontrar o mar aberto, precisam livrar-se de parte do carregamento para salvarem o todo. Dessa forma, praticamente nenhum navio consegue trazer exatamente os tesouros que recebeu. As mercadorias defenestradas, 
certamente, são escassas e preciosas, mas pouco importa: os marinheiros, em sua grande violência, cometem erros e laçam ao mar suntuosos objetos.

Assim que se parte para o porto de papel branco, novos sacrifícios são necessários mais uma vez. Vem os dignatários da alfândega e examinam o produto e julgam se é preciso devolver o carregamento. Recusam-se a deixar passar um outro para o desembarque. E, com todo esse procedimento, apenas pouca quantidade é admitida. O lugar tem as suas leis. Toda a mercadoria não tem entrada livre; de modo estrito, proíbe-se o contrabando. A entrada dos vinhos é proibida, pois os continentes de onde vem tais navios fazem vinho e alcoóis de uvas que se desenvolvem e maturam em temperatura mais arrojada. Por isso, os dignatários da alfândega não querem essas bebidas. São extremamente embriagantes. Não é conveniente a todas as cabeças. Ainda há uma empresa no lugar que detém o monopólio dos vinhos. Produz líquidos com a cor do vinho e o sabor da água, e pode-se beber durante todo o dia deles sem ficar nem um pouco alto. É uma empresa antiga alocada em grande extensão, e seus lucros são sempre abusivos.

E mais uma vez ficamos felizes quando os navios atracam no porto, mesmo com todos os sacrifícios. Pois, ao final de tudo, com insônia e muito cuidado, limitam o número dos utensílios quebrados ou partidos de acordo com a duração da viagem. Igualmente, as leis locais e as regras alfandegárias são tirânicas em relação a tudo, mas não de todo dissuasivo, e boa parte do carregamento desembarca. Os digntários da alfândega inequivocados e, diferentemente dos itens barrados, tomam dentro de falsas caixas em que se escreve uma coisa em cima e contém outra, importando alguns bons vinhos para os seletos simpósios.

Pena, pena é outra coisa. É quando tomam alguns grandes navios, com jóias de corais e velas de ébano com grandes bandeiras brancas e vermelhas içadas, cheios de tesouros, os quais nem se aproximarão do porto, seja porque todos os bens que trazem são proibidos, seja porque o porto não tem profundidade suficiente para os deixar passar. E seguem seus caminhos. Um vento favorável sopra sobre os tecidos das velas, o sol vitrifica o esplendor do ouro de suas proas, afastam-se calma e magnificamente, afastam-se de nós completamente e de nosso limitado porto.

Felizmente, tais navios são muito raros. Apenas dois ou três vemos ao longo de toda nossa vida. Esquecemos deles rapidamente. Quão brilhante é sua visão, quão rápido é o 
seu esquecimento. E quando passam alguns anos, sejam alguns dias - assim que, às vezes, de modo indolente vemos a luz e escutamos o silêncio - eventualmente retornaram para nossa escuta mental com umas voltas entusiasmadas. Não as reconhecemos de princípio e tiranizam nossa memória, lembrando-nos de que as escutamos antes. Depois de muito labor, acorda a velha recordação e lembramos o que aquelas voltas eram daquela canção que cantavam os marinheiros, belos como os heróis da Ilíada quando tomavam os grandes e sublimes navios e seguiam adiante - quem sabe para onde.

\section{Vestuário}

Em um baú ou em uma mobília de ébano precioso, colocarei e guardarei o vestuário de minha vida.

As vestes azuis. E, então, as vermelhas - as mais estupendas de todas. Depois, as amarelas. E, por fim, novamente os trajes azuis, contudo mais desbotados do que os primeiros.

Guardarei-os com piedade e muito lamento.

Ao vestir-me as negras vestes e residir em uma negra habitação, em um obscuro quarto, algumas vezes abrirei a mobília com encantamento, cobiça e desespero.

Visualizarei as roupas e recordar-me-ei da grande festa - que será, então, completamente encerrada.

Completamente encerrada. As mobílias dispersas nos quartos aleatoriamente. Pratos e copos quebrados pelo chão. Todas as velas queimadas até o final. Todo o vinho embriagado. Todos os convidados partiram. Alguns, fatigados, sentar-se-ão sozinhos, assim como eu, em escuras habitações - outros, mais cansados, irão dormir. 